of result from so-called Chellean handaxes to the finest drills. A curious instance of this flexibility is the only ground point I have which is on Card $B, 1950$, Campsite 2, stratified, line left 6 , No 2 from the left. (Provincial Muse um exhibit). Apparentl y the maker in the process of chipping found that any further work would ruin the point, so he finished it by grinding half the body.

So rationalistic was the Indian attitude to his stone industry that when he has acquired the white man's metal culture he seems to have lost all knowledge of the ancient art in a remarkably short space of time. There is a record of an Indian in the U. S. expressing the same superstition as was form erly current in Europe where artifacts when found used to be called "thunderstones"' Yet the Indians in some parts must have been still using stone points, certainly not much more than a hundred years ago. I suppose the average Indian of today would regard with contempt a collection of stone tools which his not very di stant ancestors had to use and which we so industriously collect. It seems to me there is a fine irony in it someplace.

M. A. Kittle, of Keewaten, Ontario is so interested in the welfare of the BL UE JAY thathe ins erted an advertisement in the "For Sal e" column of the Kenora Miner and News. We have received a checking copy. Thanks Mr. Kittle!

\section{The Golden Age of Mammals}

BY BRUCE A. McCORGUODALE IVuseum Assistant, Regrna.

CYPRESS HILLS REGION30 MILLION YEARS AGO

During the summer of 1950 the staff of the Provincial Museum, Regina, made two trips to the Cypress Hills region where they conducted extensive exploration andexca vations in the locality 12 miles northwest of Eastend, Sask., for the purpose of collecting fossil material of the Oligocene period - age, 30 million years.

The fossil bearing formation consists of a river delta deposit of sand, sandstone and conglomerate, which contains a great abundance of mammalian and reptillian remains, indicating that animal life of the Oligocene age was very prolific. In addition to the fact that the fossils were very abundant they were also in a remarkably excellent state of preservation and as a re sult of this the museum expeditions recovered several hundred well preserved specimens, many of which will prove of great importance in yielding information and promoting interest in the faunal life of Saskatchewan of the past.

Let us try to visualize in brief the general life forms and environmental conditions of the Saskatchewan, 30 million years ago as revealed by and in co-ordination with the specimens recovered from the Cypress Hills.

The dominant life form of the area was a large subaquatic mammal called a Titanothere. Ranging in bul $\mathrm{k}$ size up to that of a modern elephant, this great beast had blunt horns paired laterally on the forward extremity of its nose and in general body form resembled the present day Rhinoceras. Its food con sisted mostly of soft succul ent vegetation of marshy origin. This animal is rep re sented in the coll ection of fossils by several single and double lower mandibles, several horns, numerous individual teeth, a scapula, two femurs a radius and ulna, a pelvis and several ribs and verterbra The most important of these finds is a well preserved skull of an immature individual of a primitive smaller genera of the Titanothere group In addition two skull portions of Titanotheres of a more advanced genera were found.

of secondary importance but probably of greater abundance, compared to the Titanotheres, were a group of several species of Hyracodonts which were small hornless a nimals, terrestial and fleet of foot. These animals, which are early ancestors of the modern rhinoceras, are repre sented in the collection by a well preserved skull, several individual teeth, numerous lower mandibles and a few skeletal parts. In addition to these the true primitive rhinoceras, Caenopus, is represented by upper and lower mandibles.

Also in abundance during Oligocene times were several members of the deer group, represented by species of $\mathrm{Hy}$ pertragulus and Lep tomeryx which were small, swift and delicate animals no larger than the modern dog. Teeth of several species of this group were recovered from the depo sits by the Mus eum expeditions.

An extinct goup of animals, Entelodonts, related to the pig family and resembling them some what in habits and hody form, were also quite prolific in marshy area. This faunal type is represented in the discoveries by a relatively rare find, an incomplete skull and two other individual teeth.

Rodents, reptiles and small carnivores were numerous during Oligocene times as evidenced by the recovery of several small bones and teeth of these groups. 


\section{Golden Age \\ Continued}

Turtles were abundant as represented by numerous shell fragments. Vertsbrae of fish were also recovered, the largest of which measured $15 / 8$ inches in diameter.

Groups of animals of the Qliogcene specimens in the collections of the Provincial Museum are the Hya enodont (wolf like animals,) Hemisalodonts ( giant bear-like carnivores,) Dinictis ( a small member of the cat family,) and Mesohippus ( a small primitive three-toed horse).

Although there is great variety of fossil bones in this deposit, represent. ative of many species of a nimals, they are in a very disjointed, intermingled state of distribution. Several expeditions in which the National Museum, Royal Ontario Muse um of Palaeontology and Saskatchewan Provincial Museum of Natural History, Participated individually, failed to recover any complete skeltons or even a portion of one. Many of the specimens, although well preserved were eroded or fragmentary, however the most important part of the material as recovered by the provincial Museum, the jaws, skulls and teeth, were in a relatively complete condition showing little evidence of erosion.

Possibly the most interesting and intriguing feature of the collection of specimens is the immaturity of the animals when they died, as indicated by the relatively unworn condition of the teeth and incompleteness of the dental series of the jaws. This probably inicates that living was a severe trial for these animals in Oligocene times and that carnivores, unsuitable food conditions or epidemics caused the se animals to die while they were relatively young.

Although there is a great weal th of information yet to be obtained from the Cypress Hills deposits, which have been explored to a comparatively slight degree; the specimens so far recovered have contributed greatly to knowledge of faunal life of Saskatchewan 30 million years ago. Therefore, as this is the only fossil bearing deposit of Oligoceneage in Canada, the people of Saskatchewan should recognize in this formation, a great asset, to the province and to the country as a whole, in the form of an Ency clopedia of Prehistoric Natural History.

\section{Will They Be Lost Again?}

\author{
By J. H. Yerex, Clair
}

I have a modest collection of artifacts picked up around clair. It pays to advertise, for as soon as folk s knew I was interested in Indian relics they brought me many excellent specimens which would otherwise have been left aro und and eventually lost.

As is the case with most collectors I have a few museum pieces that should be preserved for those that follow after us. What will become of these pieces? Will they be thrown out in the rubbish after we pass on, or will they be properly taken care of?

It seems to me collectors should make some provision for the disposal of their collections. Perhap s something can be worked out so that anyone who wishes to could make provision for a reliable museurn to pick this material up when the collector passes on. A form could be provided to be attached to the will requesting that a certain museum be advised that such and such had gone to the "Happy Hunting Ground" and has left it his entire collection of artifacts, etc.

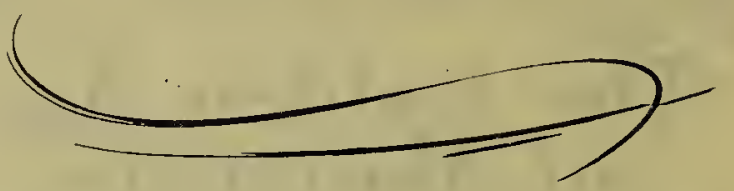

\section{Nature Artist}

The Provincial Museum is very fortunate in having engaged for a few months, this winter, the services of Robert E. Symons, an outstanding artist of wildlife, who hails from the Peace River Block, near Fort St. John, B. C. He will return to his ranch there in the sp ring.

Mr. Symons has been painting scenic backgrounds for museum wildlife exhibits. The following painting of winter birds of the Canadian Zone, which ill ustrates Mr. Bards article is an example of the type of work he produces. He has just completed a curved background, some ten or twelve feet in length for a group of deer. The painting shows a small meadow, surrounded by the trees and hills of Qu'Appelle Valley -- a scene from a secluded spot near Craven. 